\title{
PERBANDINGAN ALGORITMA BORUVKA DAN ALGORITMA SOLLIN PADA OPTIMASI KEBUTUHAN KABEL FIBER OPTIK UNIVERSITAS BENGKULU
}

${ }^{1}$ Rusdi Efendi, ${ }^{2}$ Boko Susilo, ${ }^{3}$ Yoga Adi Prasetyo

${ }^{1}$ Informatika, Universitas Bengkulu, Indonesia

Irusdi.efendi@unib.ac.id; 라bokosusilo@unib.ac.id; ${ }^{3}$ agoyunib@gmail.com;

\begin{tabular}{l} 
Article Info \\
\hline Article history: \\
Received, 19-05-2021 \\
Revised, 02-06-2021 \\
Accepted, 18-06-2021 \\
\\
Kata Kunci: \\
Minimum Spanning Tree \\
Algoritma Boruvka \\
Algoritma Sollin \\
Optimasi \\
Universitas Bengkulu
\end{tabular}

Minimum spanning tree Boruvka's Algorithm Sollin's Algorithm Optimization University of Bengkulu

\begin{abstract}
ABSTRAK
Optimasi adalah hal penting dalam suatu algoritma. Ini dapat menghemat kebutuhan dalam suatu kegiatan. Permasalahan Minimum Spanning Tree bertujuan untuk menghubungkan semua vertexs dengan bobot terkecil. Tujuan penelitian ini adalah (i) mengetahui Model graf kebutuhan kabel fiber optik Universitas Bengkulu.; (ii) membandingkan efisiensi Algoritma Boruvka dan Algoritma Sollin dalam implementasi teori Minimum Spanning Tree. Untuk mendapatkan luaran diperlukan beberapa tahap: pengumpulan data: merancang model. Hasil penelitian ini adalah (i) menghasilkan sistem aplikasi sebagai simulasi dalam menentukan optimasi panjang kabel fiber optik menggunakan Algoritma Boruvka dan Algoritma Sollin.; (ii) Total panjang kabel fiber optik awal yang telah digunakan Universitas Bengkulu dalam membangun jalur fiber optik sebelum optimasi sebesar 9.490.76061796493 meter (9,49 km).; (iii) Hasil optimasi panjang kabel fiber optik, Algoritma Boruvka dan Algoritma Sollin menghasilkan hasil optimasi yang sama yaitu $4.438,521266107877$ meter $(4,438 \mathrm{~km})$.; (iv) Terdapat hasil optimasi yang berbeda atas waktu yang diperlukan Algoritma Boruvka dan Algoritma Sollin. Algoritma Boruvka sebesar 0.5376448631287 detik dan Algoritma Sollin sebesar 0.6970238685608 detik.
\end{abstract}

\section{ABSTRACT}

Optimization is an important thing in an algorithm. This can save the need for an activity. The Minimum Spanning Tree problem aims to connect all vertices with the smallest weight. The objectives of this study are (i) to determine the graph model of the requirement for fiber optic cable at the University of Bengkulu .; (ii) comparing the efficiency of the Boruvka Algorithm and the Sollin Algorithm in the implementation of the Minimum Spanning Tree theory. To get the output, several stages are needed: data collection: designing the model. The results of this study are (i) produce an application system as a simulation in determining the length optimization of fiber optic cables using the Boruvka Algorithm and Sollin's Algorithm .; (ii) The total length of the initial fiber optic cable that has been used by the University of Bengkulu in building optical fiber lines before optimization is 9,490,76061796493 meters $(9.49 \mathrm{~km})$.; (iii) The optimization results of fiber optic cable length, Boruvka Algorithm and Sollin Algorithm produce the same optimization results, namely 4,438.521266107877 meters $(4.438 \mathrm{~km})$.; (iv) There are different optimization results for the time required by the Boruvka Algorithm and Sollin's Algorithm. The Boruvka Algorithm is 0.5376448631287 seconds and the Sollin's Algorithm is 0.6970238685608 seconds.

\section{Penulis Korespondensi:}

Rusdi Efendi,

Program Studi Informatika,

Universitas Bengkulu,

Email: rusdi.efendi@unib.ac.id 


\section{PENDAHULUAN}

Minimum Spanning Tree (MST) merupakan sebuah permasalahan graf yang telah banyak diaplikasikan baik secara langsung maupun tidak langsung daam kehidupan seharai-hari. Masalah Minimum spanning tree hampir serupa dengan masalah jalur terpendek (shortest path) yakni untuk menghubungkan seluruh simpul dalam jaringan sehingga total panjang rute diperoleh minimimum[1]. Konsep permasalahan Minimum Spanning Tree diterapkan pada graf berbobot dan tak berarah. Tujuan dari konsep Minimum Spanning Tree ini adalah menemukan jalur terpendek yang menghubungkan semua titik (verteks) yang terdapat pada sebuah graf[2].

Permasalahan Minimum Spanning Tree sederhana bisa diselesaikan dengan melakukan perhitungan manual. Namun untuk kasus yang besar dan kompleks, perhitungan manual akan sulit dilakukan karena akan memakan waktu yang lama. Oleh sebab itu dibutuhkan satu aplikasi komputer yang dapat melakukan perhitungan nilai minumum spanning tree dengan cepat dan akurat. Pada penelitian ini penyelesaian masalah Minimum Spanning Tree dengan menggunakan Algoritma Boruvka dan Algoritma Sollin[3] .

Algoritma Boruvka pertama kali diperkenalkan oleh Otakar Boruvka pada tahun 1926. Boruvka adalah salah satu teknik optimasi data dimana keberadaan tiap-tiap titik koordinat (simpul) ditentukan oleh jarak minimum. Algoritma ini dimulai dengan memeriksa setiap simpul yang terhubung dan menambahkan sisi dengan bobot terkecil pada pohon merentang, tanpa memperhatikan pada sisi yang telah ditambahkan, dan melanjutkan menggabungkan sisi lain tersebut sampai terbentuk suatu MST[4].

Algoritma Sollin pertama kali diperkenalkan oleh Sollin pada tahun 1960. Algoritma Sollin merupakan suatu Algoritma graf yang digunakan untuk menentukan pohon merentang minimum di dalam graf berbobot terhubung. Algorima ini melakukan penghapusan sisi-sisi yang tidak menyebabkan graf menjadi tidak berhubung atau membentuk sirkuit. Penghapusan sisi-sisi dilakukan pada sisi yang memiliki bobot terbesar hingga terkecil[5].

Saat ini Universitas Bengkulu terhimpun memiliki data gedung yang dilalui jalur kabel fiber optik berjumlah 46 gedung. Berikut data gedung di lingkungan Universitas Bengkulu dengan posisi koordinat gedung tersebut, seperti terlihat pada tabel 1 .

Tabel 1. Data Gedung Universitas Bengkulu

\begin{tabular}{|c|c|c|}
\hline Nomor & $\begin{array}{c}\text { Nama } \\
\text { Koordinat }\end{array}$ & Koordinat \\
\hline 1 & $\begin{array}{c}\text { Gedung } \\
\text { Kehutanan }\end{array}$ & $-3.7551972,102.2780723$ \\
\hline 2 & $\begin{array}{l}\text { Gedung } \\
\text { Rektorat }\end{array}$ & $-3.7594425,102.2724719$ \\
\hline 3 & $\begin{array}{l}\text { Gedung } \\
\text { Kelautan }\end{array}$ & $-3.7586964,102.2699949$ \\
\hline 4 & $\begin{array}{l}\text { Gedung } \\
\text { faperta }\end{array}$ & $-3.7592796,102.2695124$ \\
\hline 5 & Gedung $\mathbf{J}$ & $-3.7603775,102.2696381$ \\
\hline 45 & Gedung B & $-3.7586986,102.2676249$ \\
\hline 46 & Gedung I & $-3.7600866,102.269969$ \\
\hline
\end{tabular}

(Sumber: LPTIK Universitas Bengkulu)

Pembangunan berkelanjutan jaringan kabel fiber optik Universitas Bengkulu terus dilanjutkan mengikuti topologi Tree (pohon), dimana LPTIK sebagai pusatnya (root) kemudian dibangun jalur berdasarkan lokasi gedung yang telah dibangun dan terdekat dari LPTIK, dan gedung baru lain sebagai cabang dari gedung sebelumnya, diiringi oleh rencana pemasangan jalur kabel jaringan fiber optik[6].

Peneliti ingin melihat optimasi kebutuhan kabel dari jalur fiber optik yang telah dibangun, dengan tujuan untuk mencari jalur paling optimum yang bisa digunakan untuk rencana pemasangan jalur kabel fiber optik.Berdasarkan latar belakang diatas, Maka dari itu Algoritma Boruvka dan Algoritma Sollin akan digunakan oleh penulis sebagai algoritma perbandingan dalam optimasi kebutuhan kabel fiber optik Universitas Bengkulu.[7] 
Algoritma Boruvka adalah salah satu teknik optimasi data yang mana keberadaan tiap-tiap titik koordinat data gedung ditentukan oleh jarak minimum. Algoritma ini dimulai dengan memeriksa setiap simpul dan menambahkan sisi dengan bobot terkecil pada pohon merentang, tanpa memperhatikan pada sisi yang telah ditambahkan, dan melanjutkan menggabungkan sisi tersebut sampai terbentuk suatu MST[8].
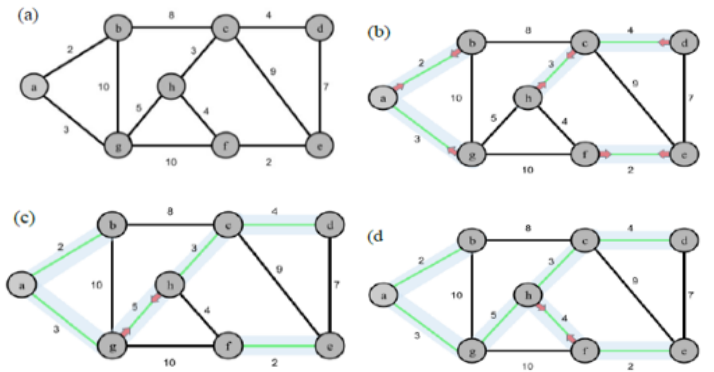

Gambar 1. (a) Graf Lengkap, (b) dan (c) Proses Minimum Spanning Tree, (d) Hasil Minimum Spanning Tree

Algoritma Sollin adalah suatu Algoritma di dalam teori graf yang digunakan untuk menentukan pohon merentang minimum di dalam graf berbobot terhubung dengan cara melakukan penghapusan sisi-sisi yang tidak menyebabkan graf menjadi tidak berhubung atau membentuk sirkuit. Penghapusan tersebut dimulai dari sisi yang memiliki bobot terbesar hingga terkecil[9].

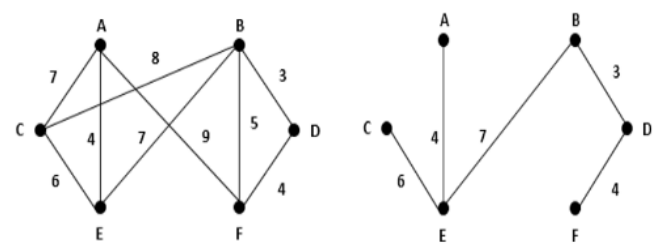

(a)

(b)

Gambar 2. (a) Graf Lengkap, (b) Hasil Minimum Spanning Tree

Untuk mengukur jarak antar 2 gedung berdasarkan titik GPS, maka digunakan Metode Haversine, dengan menegetahui dua titik GPS terakhir yang dikirim perangkat ke server[10]. Metode Haversine merupakan suatu metode untuk mengetahui jarak antar dua titik dengan memperhitungkan bahwa bumi bukanlah sebuah bidang datar namun adalah sebuah bidang yang memilki derajat kelengkungan. Penggunaan rumus ini mengasumsikan pengabaian efek ellipsoidal, cukup akurat untuk sebagian besar perhitungan, juga pengabaian ketinggian bukit dan kedalaman lembah di permukaan bumi. Berikut adalah rumus Haversine:

1. $\Delta$ lat $=$ lat2- lat1

2. $2 \Delta$ long $=$ long $2-$ long 1

3. $a=\sin 2(\Delta$ lat $/ 2)+\cos ($ lat 1$) \cdot \operatorname{Cos}($ lat 2$) \cdot \sin 2(\Delta$ long $/ 2)$

4. $c=2 \cdot a \cdot \tan 2(\sqrt{ } \mathrm{a}, \sqrt{ } 1-\mathrm{a})$

5. $d=$ R.c

Dimana:

$\mathrm{R}=$ jari-jari bumi sebesar 6371(km)

$\Delta$ lat $=$ besaran perubahan latitude

$\Delta$ long $=$ besaran perubahan longitude

$\mathrm{C}=$ kalkulasi perpotongan sumbu

$\mathrm{d}=\operatorname{jarak}(\mathrm{km})$

1 derajat $=0.0174532925$ radian 
JSAI : Journal Scientific and Applied Informatics

Vol. 4, No. 2, Juni 2021, hal. 175 181

E-ISSN: 2614-3054; P-ISSN: 2614-3062, accredited by Kemenristekdikti, Sinta 5

DOI: 10.36085

\section{METODE PENELITIAN}

A. Jenis Penelitian

Dalam penelitian ini, jenis penelitian yang akan dilakukan adalah jenis penelitian terapan atau Applied Research.

B. Metode Pengembangan Sistem

Metode pengembangan sistem yang digunakan dalam penelitian ini adalah metode Sekuensial Linier atau biasa disebut model air terjun Waterfall.

C. Metode Pengumpulan Data

Metode pengumpulan data pada penelitian terapan ini menggunakan teknik studi pustaka (Library research). Pengumpulan data ini dilakukan dengan memilih data yang sesuai dengan kebutuhan sistem yang akan dibangun yaitu informasi mengenai data koordinat gedung Universitas Bengkulu[10].

D. Metode Pengujian Sistem

Proses pengujian yang dilakukan pada aplikasi yang dibuat menggunakan black box testing. Pengujian dengan black box testing dilakukan dengan cara mengamati hasil eksekusi antarmuka melalui data uji dan memeriksa fungsional dari aplikasi yang telah dibuat[12].

\section{HASIL DAN ANALISIS}

A. Implementasi Antarmuka

\subsection{Halaman Data Koordinat}

Implementasi dari sistem yang dibangun dapat dilihat pada gambar dibawah ini.

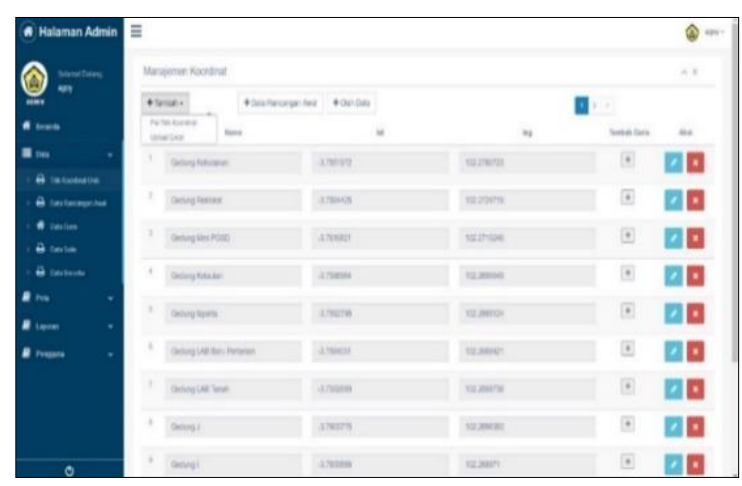

Gambar 5. Halaman data koordinat

Pada Gambar 5 User diminta untuk memasukkan data koordinat simpul titik X dan titik Y dari simpul yang nanti nya akan diproses untuk mencari nilai MST.

3.2. Halaman Data Jarak

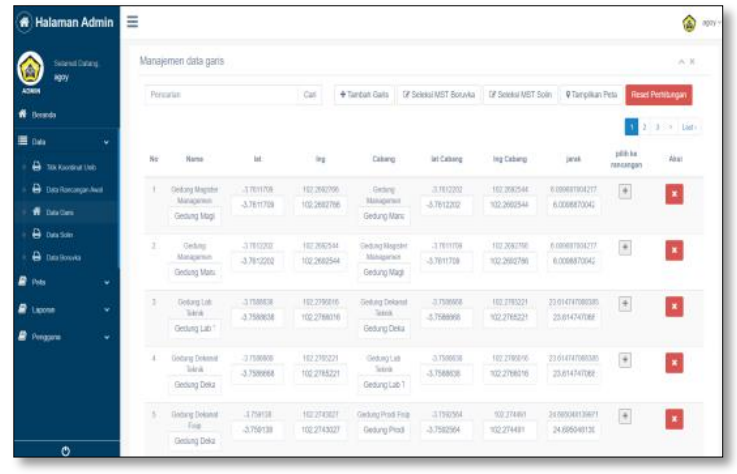

Gambar 6. Halaman data Jarak

Pada Gambar 6 menampilkan Informasi data koordinat yang telah dihitung jaraknya menggunakan Metode Haversine. 
JSAI : Journal Scientific and Applied Informatics

Vol. 4, No. 2, Juni 2021, hal. 175 181

E-ISSN: 2614-3054; P-ISSN: 2614-3062, accredited by Kemenristekdikti, Sinta 5

DOI: 10.36085

3.3

Halaman Peta Optimasi

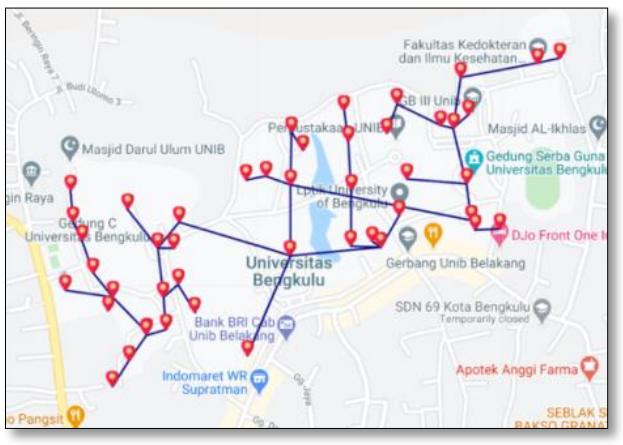

(a)

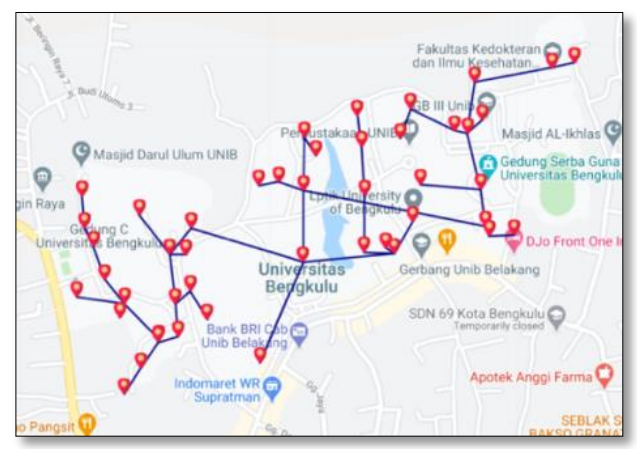

(b)

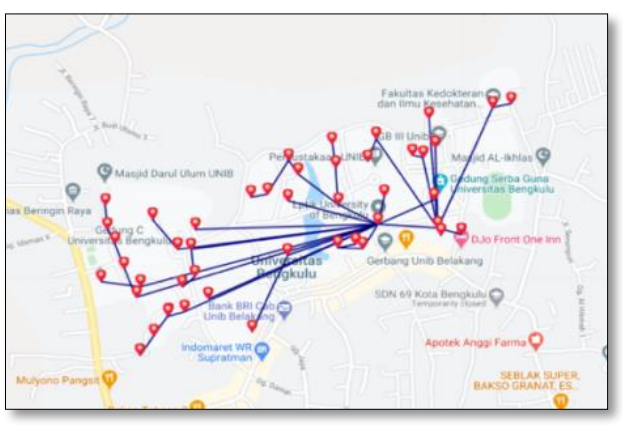

(c)

Gambar 7. Tampilan Halaman Grafik Hasil (a) Algoritma Boruvka, (b) Algoritma Sollin, (c) Data Koordinat awal

Pada pengujian ini dilakukan dengan menggunakan jumlah data simpul yang berbeda, yaitu 5 simpul, 10 simpul, 20 simpul, dan 46 simpul. Dari pengujian yang telah dilakukan, Rata-rata nilai MST yang dihasilkan oleh Algoritma Boruvka dan Algoritma Sollin adalah pada Tabel 2 sebagai berikut[13].

Tabel 2. Rata-rata jarak hasil MST

\begin{tabular}{|c|c|c|}
\hline Simpul & $\begin{array}{c}\text { MST } \\
\text { Boruvka }\end{array}$ & $\begin{array}{c}\text { MST } \\
\text { Sollin }\end{array}$ \\
\hline $\mathbf{5}$ & 1011.7821077027502 & 1011.7821077027502 \\
\hline $\mathbf{1 0}$ & 1430.547573590248 & 1430.547573590248 \\
\hline $\mathbf{2 0}$ & 2154.382682078091 & 2154.382682078091 \\
\hline $\mathbf{4 6}$ & $4.438,521266107877$ & $4.438,521266107877$ \\
\hline
\end{tabular}

Dapat dilihat dari Tabel 2 hasil pengujian MST Algoritma Boruvka dan Algoritma Sollin memberikan hasil yang sama dalam beberapa percobaan dengan data simpul yang berbeda - beda. Hal ini membuktikan bahwa 
JSAI : Journal Scientific and Applied Informatics

Vol. 4, No. 2, Juni 2021, hal. 175 181

E-ISSN: 2614-3054; P-ISSN: 2614-3062, accredited by Kemenristekdikti, Sinta 5

DOI: 10.36085

optimasi Minimum Spanning Tree Algoritma Boruvka dan Algoritma Sollin menghasilkan hasil yang sama walaupun langkah pengerjaannya berbeda[14]. Untuk rata-rata waktu proses MST Algoritma Boruvka dan Algoritma Sollin adalah pada Tabel 3 berikut ini.

Tabel 3. Rata-rata waktu proses MST

\begin{tabular}{|c|c|c|}
\hline Simpul & $\begin{array}{c}\text { Waktu proses } \\
\text { MST Boruvka }\end{array}$ & $\begin{array}{c}\text { Waktu Proses } \\
\text { MST Sollin }\end{array}$ \\
\hline $\mathbf{5}$ & 0.20134711265564 & 0.2188599014282 \\
\hline $\mathbf{1 0}$ & 0.2226488685608 & 0.2419469356537 \\
\hline $\mathbf{2 0}$ & 0.272109413145 & 0.2816401100156 \\
\hline $\mathbf{4 6}$ & 0.5376448631287 & 0.6970238685608 \\
\hline
\end{tabular}

Pada Tabel 3 waktu proses MST dengan Algoritma Boruvka dan Algoritma Sollin, Waktu yang dibutuhkan Algoritma Boruvka juga lebih cepat dari Algoritma Sollin. Hal ini dikarenakan Algoritma Boruvka yang memiliki prinsip pencarian Greedy yaitu dengan acak langsung mencari nilai minimum dari graf, sedangkan Algoritma Sollin mengurutkan dari yang terbesar kemudian mengeksekusinya menjadi Minimum Spanning Tree.[15]

B. Implementasi Sistem

Dalam implementasi sistem, aplikasi yang dibangun didukung dengan database. Desain database aplikasi optumasi kebutuhan kebal fiber optic dengan menggunakan Algoritma Boruvka dan Algoritma Sollin.

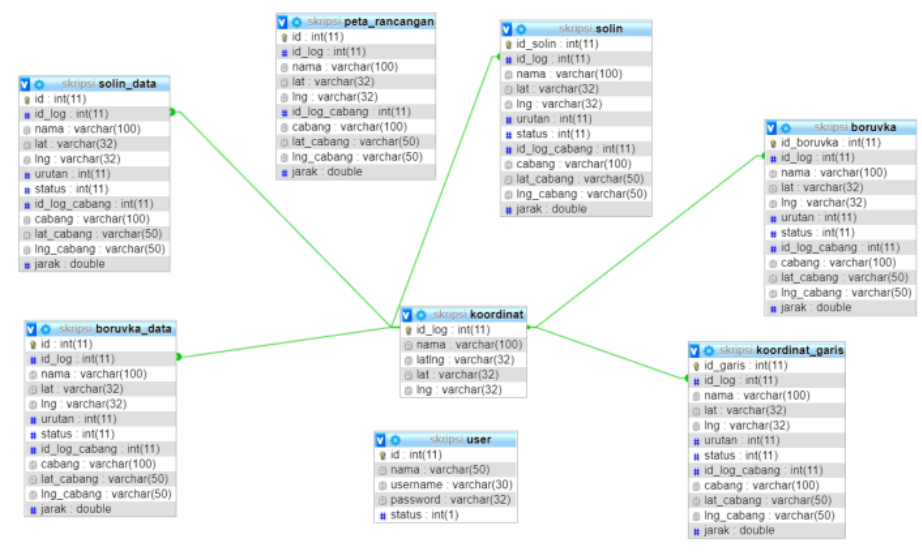

Gambar 11. Desain logika database

\section{KESIMPULAN}

Berdasarkan penelitian dan pembahasan hasil yang sudah dilakukan, maka terdapat beberapa kesimpulan yang diperoleh dari penelitian ini, diantaranya sebagai berikut: Penelitian ini telah menghasilkan sistem aplikasi sebagai simulasi dalam menentukan optimasi panjang kabel fiber optik menggunakan Algoritma Boruvka dan Algoritma Sollin. Berdasarkaan hasil pengukuran awal diperoleh total panjang kabel fiber optik awal yang telah digunakan Universitas Bengkulu dalam membangun jalur fiber optik sebelum optimasi sebesar 9.490.76061796493 meter. Dalam penelitian ini digunakan Algoritma boruvka dan algoritma Sollin untuk mengoptimasi rentang kabel fibel optik. Berdasarkan Aplikasi yang telah dibangun, total panjang kabel fiber optik sebesar 4.438,521266107877 m dan mampu meminimumkan jarak sebesar 5.052,2393518921 m (53,23 \%). Berdasarkan waktu Proses, Algoritma Boruvka menghasilkan running time sebesar 0.53764486312866 seconds dan algoritma Sollin menghasilkan running time sebesar 0.69702386856079 seconds. 


\section{REFERENSI}

[1] A. Rahmawati and Mulyono, "Minimum Spanning Tree Pada Jaringan Pendistribusian," UNNES J. Math., vol. 4, no. 2, 2015.

[2] K. Antoš, "Minimum spanning tree problem," APLIMAT 2015 - 14th Conf. Appl. Math. Proc., pp. 10-19, 2015, doi: 10.1007/978-1-4419-1153-7_200467.

[3] R. Efendi and D. Puspitaningrum, “ALGORITMA GENETIKA DALAM PENYELESAIAN,” pp. 19 .

[4] J. Nešetřil, E. Milková, and H. Nešetřilová, "Otakar Borůvka on minimum spanning tree problem: Translation of both the 1926 papers, comments, history," Discrete Math., vol. 233, no. 1-3, pp. 3-36, 2001, doi: 10.1016/S0012-365X(00)00224-7.

[5] R. D. Nim, "Menentukan Pohon Merentang Minimum Dengan Algoritma Sollin."

[6] P. Magister, M. Teknologi, B. Keahlian, M. Industri, and P. Pascasarjana, "Analisis Dan Optimasi Pada Jaringan Kabel Fiber Optik Kerumah ( Fiber To the Home ) Di Surabaya Timur Menggunakan Integer Linier Programming Analysis and Optimization on Fiber To the Home ( Ftth ) Network At East Surabaya Using Integer," 2016.

[7] D. W. Nugraha, "Aplikasi Algoritma Prim untuk Menentukan Minimum Spanning Tree Suatu Graf Berbobot Berorientasi Objek,” Tek. Elektro UNTAD Palu, vol. 1, no. 2, pp. 70-79, 2011, [Online]. Available: deny_wiria_nugraha@yahoo.co.id.

[8] D. N. U. R. Afandi, "Penerapan algoritma boruvka metode contracted graph dalam menentukan minimum spanning tree," 2017.

[9] W. Anggraeni, "Aplikasi Algoritma Sollin Dalam Pencarian Pohon Perentang Minimum Provinsi Jawa Tengah," Fakt. Exacta, vol. 8, no. 4, pp. 381-391, 2015.

[10] E. Hasmin, "Informasi Kepadatan Lalu Lintas Berbasis Komunitas," Semin. Nas. Inform., vol. 1, no. 1, pp. 648-653, 2017.

[11] Y. Yulianto, R. Ramadiani, and A. H. Kridalaksana, "Penerapan Formula Haversine Pada Sistem Informasi Geografis Pencarian Jarak Terdekat Lokasi Lapangan Futsal," Inform. Mulawarman J. Ilm. Ilmu Komput., vol. 13, no. 1, p. 14, 2018, doi: 10.30872/jim.v13i1.1027.

[12] F. Mahardika, "Penerapan Teori Graf Pada Jaringan Komputer Dengan Algoritma Kruskal," J. Inform. J. Pengemb. IT, vol. 4, no. 1, pp. 48-53, 2019, doi: 10.30591/jpit.v4i1.1032.

[13] M. Faculty and M. Email, “COMPERATIVE OF PRIM'S, KRUSKAL'S AND BORUVKA'S ALGORITMA TO SOLVE MINIMUM SPANNING TREE PROBLEMS Faridawaty Marpaung, Arnita,Wirdatull Jannah Idris,” vol. 10, no. 2, pp. 80-89, 2019.

[14] Wamiliana, D. Kurniawan, and C. S. N.F, "Perbandingan Kompleksitas Algoritma Prim, Algoritma Kruskal , Dan Algoritma Sollin Untuk Menyelesaikan Masalah Minimum Spanning Tree,” vol. 2, no. 1, pp. 60-67, 2014.

[15] M. Abrori and N. Ubaidillah, "Pengujian Optimalisasi Jaringan Kabel Fiber Optic Di Universitas Islam Indonesia Menggunakan Minimum Spanning Tree," J. Fourier, vol. 3, no. 1, p. 49, 2014, doi: 10.14421/fourier.2014.31.49-58. 